\title{
Multiplex PCR-based detection of Salmonella Typhimurium and Salmonella Enteritidis in Specific Pathogen Free (SPF) and Commercial Eggs
}

Jakeen El Jakee ${ }^{1}$, Diaa El Din Gad Khelfa ${ }^{2}$, Monier Mohammed El-Safty ${ }^{3}$, Ahmed Adel Seida ${ }^{{ }^{*}}$, Sherif Marouf ${ }^{1}$, Jens Hahne $^{4}$, Zafar Mahmood ${ }^{5}$ and Sarah Sobhy Nagy ${ }^{3}$

${ }^{1}$ Department of Microbiology and Immunology, Faculty of Veterinary Medicine, Cairo University, Egypt

${ }^{2}$ Department of Poultry and Rabbit Diseases, Faculty of Veterinary Medicine, Cairo University, Egypt

${ }^{3}$ Quality Control of SPF Eggs Department in Central Laboratory for Evaluation of Veterinary Biologics (CLEVB) Abassia, Cairo, Egypt

${ }^{4}$ Institute of Cancer Research, London, England

${ }^{5}$ Graduate School of Life Sciences, University of Würzburg, Würzburg, Germany

"Corresponding author: Ahmed Adel Seida, Microbiology and Immunology Department, Faculty of Veterinary Medicine, Cairo University, Giza, P.O. 12211, Egypt, Tel: 0020237175004; E-mail: Seida_AA@cu.edu.eg

Received date: February 23, 2016; Accepted date: March 28, 2016; Published date: April 04, 2016

Copyright: ( 2016 El Jakee J, et al. This is an open-access article distributed under the terms of the Creative Commons Attribution License, which permits unrestricted use, distribution, and reproduction in any medium, provided the original author and source are credited.

\begin{abstract}
Salmonella serovars are one of the major bacterial causes of food borne diseases. Eggs are commonly identified as food sources responsible for salmonellosis outbreaks. This study aimed to isolate Salmonella Typhimurium and Salmonella Enteritidis from 1750 hens' eggs, and use of multiplex polymerase chain reaction (Multiplex PCR) in the identification of different Salmonella serovars from eggs. The incidence of salmonellae among the Balady eggs yolk was $1.3 \%$, while the incidence was $1.2 \%$ among white and brown eggs samples (each). $S$. Typhimurium and $S$. Enteritidis were identified ( 0.6 and $0.5 \%$ respectively). The isolates were confirmed using fliC, sefA genes and gene specific for genus Salmonella. All albumen samples negative for isolation of isolation of salmonellae by culture method were retested by PCR.

From the retested albumen samples $3 \%, 8.4 \%$ and $6 \%$ collected from Balady, white and brown eggs respectively were positive for Salmonella serovars using Multiplex PCR. No salmonellae could be detected from specific pathogen free (SPF) eggs using both PCR and conventional methods.
\end{abstract}

Keywords: Eggs; SPF; Multiplex PCR; S. Typhimurium; S. Enteritidis

\section{Introduction}

Contamination of eggs has been identified as one of the major causes of food borne Salmonella [1]. In the United States all cases of Salmonella contamination of eggs were reported to the Centre for Disease Control and Prevention [2]. There are two pathways for eggs to become internally contaminated with Salmonella, direct contamination occurs during the formation of an egg in the ovary and oviduct of hens; whereas, indirect contamination occurs after penetration of salmonellae the egg shell membrane [3].

Salmonella Pullorum or Salmonella Gallinarum in the ovules before ovulation likely and probably constitutes the chief mode of vertical transmission [4]. The majority of human illnesses caused by Salmonella Enteritidis are attributed to the consumption of contaminated eggs [5].

The aim of this study was to determine $S$. Typhimurium and $S$. Enteritidis in eggs of Balady, white, brown and SPF layer breed collected from different governorates using conventional microbiology detection compared to that detected using Multiplex-PCR technique.

\section{Materials and Methods}

\section{Samples}

Total 1750 eggs were collected from Balady $(n=1000)$, brown $(n=250)$, white $(n=250)$ and SPF $(n=250)$ eggs from Kafr El sheikh, Elqalubia, El Monofia, Al Fayoum, EL Menia farms and from the SPF egg producing project (Koom Ousheem-Al Fayoum), Egypt. Egg yolk and egg albumins were collected from each egg and these samples were cultured within $24 \mathrm{hrs}$ from collection.

\section{Identification of Salmonellae}

Under complete sterile condition each egg was cleaned by cotton swab soaked in alcohol. The egg was broken in a Petri dish plate then egg yolk and egg albumin were collected by two separate syringes. Detection of Salmonella was carried out according to ISO 6579: (2002) [6]. The samples were cultured on xylose lysine deoxycholate (XLD) and brilliant green agar (BGA) plates. The suspected colonies on XYD and BGA plates were picked up for microscopically examination by Gram's stain before being transferred into semisolid and slope agar for preservation and further identification. Salmonella isolates were identified biochemically and serologically as reported in previous literatures $[7,8]$. 
Citation: El Jakee J, Khelfa DEDG, El-Safty MM, Seida AA, Marouf S, et al. (2016) Multiplex PCR-based detection of Salmonella Typhimurium and Salmonella Enteritidis in Specific Pathogen Free (SPF) and Commercial Eggs. Clin Microbiol 5: 241. doi: $10.4172 / 2327-5073.1000241$

Page 2 of 5

Detection of the genus Salmonella using the multiplex PCRbased assay

DNA was extracted from the examined samples using QIAamp DNA Mini kit (catalog no. 51304, QIAGEN GmbH, Germany) according to manufactures recommendations. The PCR was conducted according to modified Oliveira protocol using specific primers as shown in table 1 [9]. The primers were prepared by Sigma Company in Germany according to Soumet et al., [10] and amplified PCR products were analyzed gel electrophoresis in $1 \%$ agarose gel.

\begin{tabular}{|c|c|c|c|}
\hline Target sequence & Primer sets & Primer sequence $\mathbf{5}^{\prime} \rightarrow \mathbf{3}^{\prime}$ & Amplification region (bp) \\
\hline \multirow{2}{*}{ Random sequence } & ST11 & GCCAACCATTGCTAAATTGGCGCA & 429 \\
\cline { 2 - 4 } & ST15 & GGTAGAAATTCCCAGCGGGTACTGG & 559 \\
\hline \multirow{2}{*}{ fliC gene } & Fli15 & CGGTGTTGCCCAGGTTGGTAAT & 312 \\
\cline { 2 - 4 } & Tym & ACTCTTGCTGGCGGTGCGACTT & 3 \\
\hline
\end{tabular}

Table 1: Primers used for the detection of Salmonella species [10].

\section{Results}

\section{Detection of the Salmonella serovars among the examined eggs}

The highest number of isolates was recovered from the Balady eggs collected from Kafr El sheik (2.7\%) and EL Monofia (3\%). The incidence was $1.2 \%$ from both the white and brown eggs as shown in table 2. All isolates of salmonellae were recovered from yolk samples only. The results revealed that 13 serovars (1.3\%) were isolated from the yolk samples of Balady eggs and serotyped as $7 S$. Typhimurium and $6 S$. Enteritidis. Three serovars (1.2\%) were isolated from the yolk of white eggs and serotyped as $2 S$. Typhimurium and one $S$. Enteritidis. Also 3 serovars (1.2\%) were isolated from the yolk of brown eggs and serotyped as $2 S$. Enteritidis and one $S$. Typhimurium as shown in table 3. It is also clear that all SPF eggs were free from salmonellae infections.

\begin{tabular}{|c|c|c|c|c|}
\hline Type of eggs & Number of the examined eggs & Number of Salmonella isolates & Percentage (\%) & Governorates \\
\hline \multirow{3}{*}{ White } & 250 & 3 & $1.20 \%$ & \\
\hline & 150 & 2 & $1.30 \%$ & Kafr El sheik \\
\hline & 100 & 1 & $1 \%$ & Elqalubia \\
\hline \multirow{3}{*}{ Brown } & 250 & 3 & $1.20 \%$ & \\
\hline & 100 & 1 & $1 \%$ & Elqalubia \\
\hline & 150 & 2 & $1.30 \%$ & El Monofia \\
\hline \multirow{6}{*}{ Balady } & 1000 & 13 & $1.30 \%$ & \\
\hline & 250 & 2 & $0.80 \%$ & EL Sharkia \\
\hline & 250 & 2 & $0.80 \%$ & Al Fayoum \\
\hline & 250 & 2 & $0.80 \%$ & EL Menia \\
\hline & 150 & 4 & $2.70 \%$ & Kafr EL Sheik \\
\hline & 100 & 3 & $3 \%$ & EL Monofia \\
\hline SPF & 250 & - & $0 \%$ & Al Fayoum \\
\hline Total & 1750 & 19 & $1.09 \%$ & \\
\hline
\end{tabular}

Table 2: Prevalence of Salmonella serovars recovered from the examined eggs. 
Citation: El Jakee J, Khelfa DEDG, El-Safty MM, Seida AA, Marouf S, et al. (2016) Multiplex PCR-based detection of Salmonella Typhimurium and Salmonella Enteritidis in Specific Pathogen Free (SPF) and Commercial Eggs. Clin Microbiol 5: 241. doi: $10.4172 / 2327-5073.1000241$

Page 3 of 5

\section{Confirmation of the isolates using multiplex PCR}

Using primers specific for Genus Salmonella, for $S$. Enteritidis (sefA gene) and $S$. Typhimurium (filC gene) serovars, Multiplex PCR was used to identify the specific isolates. All isolates were positive for amplification of 429 bp specific for Genus Salmonella. Furthermore, $S$. Enteritidis and $S$. Typhimurium isolates were positive for amplification of $312 \mathrm{bp}$ and $559 \mathrm{bp}$ respectively (Figure 1).

\begin{tabular}{|c|c|c|c|c|c|c|}
\hline \multirow{3}{*}{ Type of eggs } & \multicolumn{4}{|c|}{ Salmonella serovars } & \multicolumn{2}{|c|}{ Total } \\
\hline & \multicolumn{2}{|c|}{ S. Enteritidis } & \multicolumn{2}{|c|}{ S. Typhimurium } & \multirow[b]{2}{*}{ No. } & \multirow[b]{2}{*}{$\%$} \\
\hline & No. & $\%$ & No. & $\%$ & & \\
\hline Balady eggs(1000) & 6 & 0.6 & 7 & 0.7 & 13 & 1.3 \\
\hline White eggs(250) & 1 & 0.4 & 2 & 0.8 & 3 & 1.2 \\
\hline Brown eggs (250) & 2 & 0.8 & 1 & 0.4 & 3 & 1.2 \\
\hline SPF eggs (250) & - & 0 & - & 0 & - & 0 \\
\hline Total 1750 & 9 & 0.5 & 10 & 0.6 & 19 & 1.3 \\
\hline
\end{tabular}

Table 3: Salmonella serovars isolated from the egg yolk of the Balady, brown and white eggs.

\section{$\begin{array}{lllllllllllll}1 & 2 & 3 & 4 & 5 & 6 & 7 & 8 & 9 & 10 & 11 & 12\end{array}$}

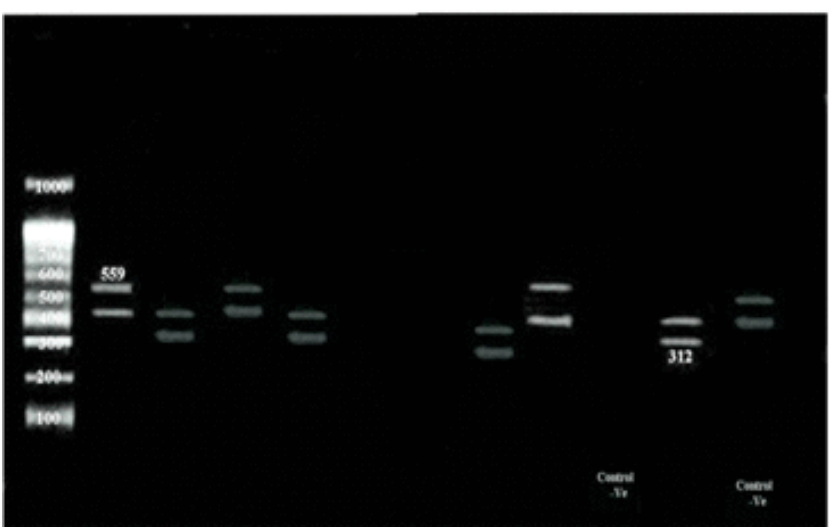

Figure 1: Agarose gel electrophoreses showing amplification of 429, 559 and 312 bp fragments from the extracted DNA of Salmonella isolates. Lane 1: 100 bp DNA marker (GibcoBRL), Lanes 2, 4, 9 and 12: positive amplification of $559 \mathrm{bp}$ fragment of $S$. Typhimurium isolates, Lanes 3, 5, 8 and 11: positive amplification of $312 \mathrm{bp}$ fragments of S. Enteritidis isolates, Lane 12: positive control (S. Typhimurium ATCC 13076), Lanes 6 and 7 negative control $(S$. aureus ATCC 29737) and Lane10: negative control (distilled water).

\section{Direct detection of the Salmonella from egg albumin using the multiplex PCR}

All albumen samples collected from the examined eggs were retested by m PCR for detection of $S$. Enteritidis and $S$. Typhimurium. It is clear that $66(4.4 \%)$ out of 1500 albumin samples were positive for salmonellae, $48(3.2 \%)$ and $18(1.2 \%)$ samples were positive for $S$. Enteritidis and $S$. Typhimurium respectively. Among the Balady eggs,
$21(2.1 \%)$ and $9(0.9 \%)$ samples were positive for $S$. Enteritidis and $S$. Typhimurium respectively. From the white egg albumin samples, 17 $(6.8 \%)$ and $4(1.6 \%)$ samples were $S$. Enteritidis and $S$. Typhimurium respectively. The albumin samples of the brown eggs recorded $10(4 \%)$ and $5(2 \%)$ positive samples for $S$. Enteritidis and $S$. Typhimurium respectively as shown in table 4 and figure 2 .

\section{$\begin{array}{llllllllllll}1 & 2 & 3 & 4 & 5 & 6 & 7 & 8 & 9 & 10 & 11 & 12\end{array}$}

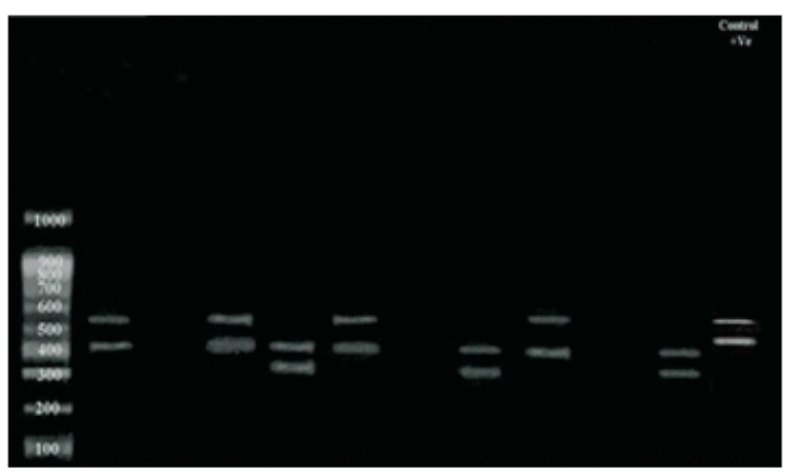

Figure 2: Agarose gel electrophoreses showing amplification of 429 bp, $559 \mathrm{bp}$ and $312 \mathrm{bp}$ fragments from the egg albumen samples. Lane 1: 100bp DNA marker (GibcoBRL), Lanes 2, 4, 5, 6, 8, 9,11 and 12: positive amplification of 429 bp fragment of Salmonella species, Lanes 2, 4, 6, 9 and 12: positive amplification of $559 \mathrm{bp}$ fragment of $S$. Typhimurium, Lanes 5, 8 and 11: positive amplification of $312 \mathrm{bp}$ fragment of $S$. Enteritidis, Lane 12: positive control $S$. Typhimurium (ATCC 13076), Lane 10: negative control $S$. aureus (ATCC 29737), Lanes 3 and 7: negative control distilled water. 
Citation: El Jakee J, Khelfa DEDG, El-Safty MM, Seida AA, Marouf S, et al. (2016) Multiplex PCR-based detection of Salmonella Typhimurium and Salmonella Enteritidis in Specific Pathogen Free (SPF) and Commercial Eggs. Clin Microbiol 5: 241. doi: $10.4172 / 2327-5073.1000241$

Page 4 of 5

\begin{tabular}{|c|c|c|c|c|}
\hline \multirow{2}{*}{ Types of egg } & \multirow{2}{*}{ Number of examined albumin samples } & \multicolumn{3}{|c|}{ Amplified PCR product } \\
\cline { 3 - 5 } & & $429 \mathrm{bp}$ (Genus Salmonella) $\mathrm{n}(\%)$ & $312 \mathrm{bp}(\mathrm{S}$. Enteritidis) $\mathrm{n}(\%)$ & $559 \mathrm{bp}(\mathrm{S}$. Typhimurium) $\mathrm{n}(\%)$ \\
\hline Balady & 1000 & $30(3 \%)$ & $21(2.1 \%)$ & $9(0.9 \%)$ \\
\hline White & 250 & $21(8.4 \%)$ & $17(6.8 \%)$ & $4(1.6 \%)$ \\
\hline Brown & 250 & $15(6 \%)$ & $10(4 \%)$ & $5(2 \%)$ \\
\hline Total & 1500 & $66(4.4 \%)$ & $48(3.2 \%)$ & $18(1.2 \%)$ \\
\hline
\end{tabular}

Table 4: Direct detection of the Salmonella from egg albumin samples using the multiplex PCR.

\section{Discussion}

Salmonella contamination of eggs has been identified as a public health concern worldwide. Globally, Salmonella is one of the most prevalent causes of food borne illness [3].

The present data revealed that 19 Salmonella isolates were isolated from 1500 examined Balady, white and brown eggs (1.3\%). Earlier Salmonella was isolated by Jones et al., [11] from $72.0 \%$ of all samples collected from the laying house environment (flush water, ventilation fan, egg belt, and egg collector samples).

It is clear that $10 S$. Typhimurium and $9 S$. Enteritidis were identified serologically with incidence of 0.6 and $0.5 \%$ respectively. Salmonella Enteritidis and $S$. Typhimurium as well as other serotypes have been isolated from egg shells and egg content [12].

The two most commonly identified causative agents of food borne salmonellosis are Salmonella enterica serotypes Typhimurium and Enteritidis [13]. Both serotypes have the ability to colonize the reproductive organs of hens and are major causes of food borne illness [3].

$S$. Enteritidis is more commonly linked to contaminated eggs, except in Australia, where the majority of egg-related food borne salmonellosis is caused by $S$. Typhimurium [14-16]. It has been concluded that $S$. Enteritidis could penetrate the egg shell easier than other serotypes so they supposed that horizontal transmission of Salmonella in eggs is of less importance than the vertical transmission [17]. Hen's eggs are the most important vehicle of the $S$. Enteritidis infection in humans [18].

The most commonly used technique for Salmonella detection is the conventional culture technique. The polymerase chain reaction (PCR) method required only 2 days, compared to the 5 days required by conventional selective enrichment and serological tests for Salmonella serovars the culture method and the sensitivity of this assay was approximately less than $1 \mathrm{CFU} / 600 \mathrm{~g}$ of egg pool [19].

A polymerase chain reaction for the specific detection of the gene sequence, sef $A$, encoded by all isolates of Salmonella Enteritidis, was developed previously by Woodward and Kirwan [20].

The PCR assay proved by Seo et al., [19] to be a rapid and highly sensitive test for detection of low concentrations of Salmonella in egg samples. PCR represents a rapid procedure to detect Salmonella in a food sampled. In this study, sefA and filC genes were amplified to confirm the isolates as well as to detected $S$. Enteritidis and $S$. Typhimurium directly from egg albumen samples. While no albumen sample was detected by the microbiological method, $21(2.1 \%)$ and 9 (0.9\%) samples from Balady eggs, 17 (6.8\%) and 4 (1.6\%) samples from white egg albumin samples and $10(4 \%)$ and $5(2 \%)$ from brown eggs were positive for $S$. Enteritidis and $S$. Typhimurium respectively. PCR is a sensitive method with a superior ability to detect Salmonella spp. in the presence of other competing bacteria [21,22].

All examined albumen samples were negative for isolation of salmonellae by culture method. Egg white proteins, such as lysozyme and ovotransferrin, are well known to play important roles in defense against bacterial invader Baron et al. [23]. Using PCR, 3\%, 8.4\% and $6 \%$ albumen samples collected from Balady, white and brown eggs respectively were positive for Salmonella serovars. Salmonella DNA could be detected from infertile eggs which incidence was higher than that by bacteria isolation [24]. Salmonella strains grow better in fresh egg white than in egg white of 2 or 3 weeks old [17]. In fresh eggs, only few salmonellas are present and as albumen is an iron-restricted environment, growth will only occurs once storage-related changes to vitelline membrane permeability, which allows salmonellae to invade yolk contents, have taken place, when this happens high populations are achieved in both yolk contents and albumen [25]. In the present study 48 and 18 cases were positive to $S$. Enteritidis and $S$. Typhimurium respectively using $\mathrm{m}$ PCR. Baron et al., [23] reviewed critically assesses the available evidence on the antimicrobial components of egg white. In addition, mechanisms employed by $S$. Enteritidis to resist egg white exposure are also considered along with various genetic studies that have shed light upon egg white resistance systems. The egg-contamination capacity of $S$. Enteritidis includes its exceptional survival capability within the harsh conditions provided by egg white [23].

Multiplex PCR is a sensitive method with a superior ability to detect Salmonella spp. in the presence of other competing bacteria. Although Salmonella contamination of eggs is a complex issue that is influenced by many variables, making it difficult to implement appropriate management strategies. Further research is required to explore different protocols to ensure control of Salmonella through temperature and $\mathrm{pH}$ of food products. There is also a need to reeducate food handlers and consumers of the risk from raw eggs and cross contamination of food products and reduce the public health risk.

\section{Conflict of Interest}

The authors declare that there is no conflict of interests.

\section{Acknowledgement}

The authors gratefully acknowledge Dr. Zafar Mahmood from Germany and Dr. Jens Hahne from England for their scientific input, 
Citation: El Jakee J, Khelfa DEDG, El-Safty MM, Seida AA, Marouf S, et al. (2016) Multiplex PCR-based detection of Salmonella Typhimurium and Salmonella Enteritidis in Specific Pathogen Free (SPF) and Commercial Eggs. Clin Microbiol 5: 241. doi: $10.4172 / 2327-5073.1000241$

Page 5 of 5

experimental planning and revising the manuscript critically for important intellectual content.

\section{References}

1. Howard ZR, O’Bryan CA, Crandall PG, Ricke SC (2012) Salmonella Enteritidis in shell eggs: Current issues and prospects for control. Food Res Int 45: 755-764.

2. Food and Drug Administration, HHS (2009) Prevention of Salmonella Enteritidis in shell eggs during production, storage, and transportation. Final rule. Fed Regist 74: 33029-33101.

3. Whiley H, Ross K (2015) Salmonella and eggs: from production to plate. Int J Environ Res Public Health 12: 2543-2556.

4. Shivaprasad HL (2008) Bacterial Diseases. Diseases of poultry. Black well publishing, USA.

5. Gast RK, Guraya R, Jones DR, Anderson KE (2014) Contamination of eggs by Salmonella Enteritidis in experimentally infected laying hens housed in conventional or enriched cages. Poult Sci 93: 728-733.

6. ISO 6579 (2002) Microbiology of food and animal feeding stuffs. Horizontal method for the detection of Salmonella spp. (4thedn.): International Organization for Standardization.

7. Quinn PJ, Markey BK, Carter ME, Donnelly WJC, Leonard FC, et al. (2002) Veterinary microbiology and microbial disease. (1stedn.), Blackwell Science Ltd., USA.

8. Popoff MY, Bockemühl J, Gheesling LL (2004) Supplement 2002 (no. 46) to the Kauffmann-White scheme. Res Microbiol 155: 568-570.

9. Oliveira SD, Santos LR, Schuch DM, Silva AB, Salle CT, et al. (2002) Detection and identification of salmonellas from poultry-related samples by PCR. Vet Microbiol 87: 25-35.

10. Soumet C, Ermel G, Rose N, Rose V, Drouin P, et al. (1999) Evaluation of a multiplex PCR assay for simultaneous identification of Salmonella sp., Salmonella Enteritidis and Salmonella Typhimurium from environmental swabs of poultry houses. Lett Appl Microbiol 28: 113-117.

11. Jones FT, Rives DV, Carey JB (1995) Salmonella contamination in commercial eggs and an egg production facility. Poult Sci 74: 753-757.

12. Loongyai W, Promphet K, Kangsukul N, Noppha R (2010) Detection of Salmonella in Egg Shell and Egg Content from Different Housing Systems for Laying Hens. International Journal of Biological, Biomolecular, Agricultural, Food and Biotechnological Engineering 4: 232-234.
13. Galis AM, Marcq C, Marlier D, Portetelle D, Van I, et al. (2013) Control of Salmonella contamination of shell eggs-Preharvest and postharvest methods: A review. Compr Rev Food Sci Food Saf 12: 155-182.

14. Gantois I, Eeckhaut V, Pasmans F, Haesebrouck F, Ducatelle R, et al. (2008) A comparative study on the pathogenesis of egg contamination by different serotypes of Salmonella. Avian Pathol 37: 399-406.

15. Wales AD, Davies RH (2011) A critical review of Salmonella Typhimurium infection in laying hens. Avian Pathol 40: 429-436.

16. Moffatt CRM, Musto J (2013) Salmonella and egg-related outbreaks. Microbiol Aust 34: 94-98.

17. Duboccage L, Heyndrickx M, Grijspeerdt K, Herman L (2001) Growth of Salmonella in egg white. Meded Rijksuniv Gent Fak Landbouwkd Toegep Biol Wet 66: 531-534.

18. Gantois I, Ducatelle R, Pasmans F, Haesebrouck F, Gast R, et al. (2009) Mechanisms of egg contamination by Salmonella Enteritidis. FEMS Microbiol Rev 33: 718-738.

19. Seo KH, Valentin-Bon IE, Brackett RE, Holt PS (2004) Rapid, specific detection of Salmonella Enteritidis in pooled eggs by real-time PCR. J Food Prot 67: 864-869.

20. Woodward MJ, Kirwan SE (1996) Detection of Salmonella Enteritidis in eggs by the polymerase chain reaction. Vet Rec 138: 411-413.

21. Rozila A, Hartini AW, Tan DY, Wee SK (2007) Rapid Molecular Detection of Salmonella Isolated from Poultry Farm. The 19th Veterinary Association Malaysia Congress, Malaysia.

22. Gallegos-Robles MA, Morales-Loredo A, Alvarez-Ojeda G, Osuna-García JA, Martínez IO, et al. (2009) PCR detection and microbiological isolation of Salmonella spp. from fresh beef and cantaloupes. J Food Sci 74: M37-40.

23. Baron F, Nau F, Guérin-Dubiard C, Bonnassie S, Gautier M, et al. (2016) Egg white versus Salmonella Enteritidis! A harsh medium meets a resilient pathogen. Food Microbiol 53: 82-93.

24. Tuchili LM, Kodama H, Sharma RN, Takatori I, Pandey GS, et al. (1996) Detection of Salmonella DNA in chicken embryos and environmental samples by polymerase chain reaction. J Vet Med Sci 58: 881-884.

25. Humphrey TJ (1994) Contamination of egg shell and contents with Salmonella Enteritidis: a review. Int J Food Microbiol 21: 31-40. 